\title{
MITO E TRAGÉDIA EM TUCÍDIDES: A LEITURA DE FRANCIS M. CORNFORD
}

\author{
FRANCISCO MURARI PIRES* \\ Faculdade de Filosofia, Letras e Ciências Humanas \\ Universidade de São Paulo
}

\begin{abstract}
RESUMO: Delineamento analítico da abordagem interpretativa de um padrão de composição trágica na obra de Tucídides por Francis Macdonald Cornford apreciada no enquadramento de sua historicidade epistemológica de integração nos Ritualistas de Cambridge.
\end{abstract}

PALAVRAS-CHAVE: Tucídides; Francis M. Cornford; história; tragédia; Ritualistas de Cambridge.

Por um bom tempo, ao longo do século XIX adentrando o XX, a obra de Tucídides valeu, a nós modernos, por seu vislumbre epistemológico excepcional: projeto, mesmo que milenarmente antecipado, de uma Ciência da História. Na História tucidideana reconhecíamos nossos princípios e preceitos de cientificidade historiográfica. O primado irrestrito, quase obsessivo, de afirmar a verdade dos fatos, alcançados em sua singularidade unívoca de acontecimentos cronologicamente ordenados. O espírito de crítica conformado em método analítico de comprovação (por apuração e depuração) de veracidade dos relatos e informes históricos, pautando-se pelos melhores padrões de rigor e exatidão de uma práxis que almeja à objetividade de sua escrita. A hermenêutica imantada por uma tese de causalidade imanente da História, a alijar dela ou as erranças de qualquer metafísica ou os desvios de qualquer ideologia, de modo a que os fatos mesmos revelassem sua história. E, consideradas particularmente as constâncias e persistências dos modos das ações e comportamentos da natureza humana, já apontados pelo próprio Tucídides, até mesmo uma História com aspirações a, talvez, alcançar a formulação de leis gerais dos fenômenos históricos. Tucídides, pois, "o primeiro Historiador moderno, justo porque científico".

Então, ano de 1907, uma voz soou altamente dissonante em meio à sinfonia do coro da hermenêutica "positivista", especialmente zelosa da cientificidade 
tucidideana: Thucydides Mythistoricus, assim Francis Macdonald Cornford intitulou sua obra. Título provocativo, viria a admitir o próprio Cornford, anos mais tarde, em 1921, ao referir-se a essa sua obra inaugural. ${ }^{1}$ Certamente, pois, o que Tucídides cuidara, decidido, por dissociar, história e mito, dela (história) o extirpando (mito), Cornford agora novamente nele fazia conjugar, assim refundidos os dois termos, mito e história, por aquele neologismo formular, espécie de hibridismo conceitual algo monstruoso devido a essa sua adjunção de entidades mutuamente inconciliáveis.

Se o alvo da polêmica tramada pelo Mythistoricus de Cornford apontava sua mira mais direta para o próprio Tucídides, seu alcance vinha ricochetear em objetos mais longínquos, alvejando também seus avatares historiográficos do tempo presente, do mundo contemporâneo, de fins do século XIX e inícios do XX, cultuadores do historiador ateniense ${ }^{2}$, justamente na medida em que o celebravam como "pai fundador" da ciência da história, quem a livrara das amarras primitivas do mito.

Ora, ao que intriga Cornford em sua obra, estes críticos modernos, de vocação historiográfica, tinham sido vítimas de uma "falácia modernista": projetavam, em Tucídides, as nossas categorias e noções de cientificidade, derivadas em seus fundamentos da biologia darwiniana e da física contemporânea. Tucídides (como, aliás, todo o mundo grego do século $\mathrm{V}$ ) desconhecia o que fosse propriamente uma categoria de causalidade histórica última, real e efetiva, assim apreendida graças a um exercício de juízo crítico, como bem o fazem os historiadores modernos.

A história de Tucídides, sentencia Cornford, não comporta um enfoque científico, pois carente de seu correspondente aparato conceitual, o qual se firmara apenas graças aos conhecimentos acumulados na época moderna. "Não era ainda o tempo para a investigação das causas e para a elaboração de construções hipotéticas", sentencia Cornfod (1907, p. 76). Entender, então, o livro I da Guerra dos Peloponésios e Atenienses como a narrativa tucidideana das causas reais da guerra, aventa Cornford, ilude-se pelas miragens dessas projeções da ótica moderna, uma verdadeira "falácia modernista". A história tucidideana, sugere Cornford, supõe e remete a determinação de sua hermenêutica narrativa a outros padrões e paradigmas de inteligibilidade, que não propriamente os da ciência histórica contemporânea.

Tucídides, diz Cornford, bem que começara sua obra imbuído de propósitos de "temperamento científico", projetando-a originariamente como uma espécie de manual de estrategia militar e de ensinamentos políticos sob forma analística, "a mere journal of the war" (CORNFORD, 1907, p. 79): apenas um registro de 
fatos verídicos, positivamente apreendidos, quer dizer, fatos cuja apreensão era desviada quer, por um lado, de explanações de ordem religiosa em termos de causas sobrenaturais ou intervenções divinas, quer, de outro, de especulações de ordem filosófica por redução a sistemas e teorizações abstratas (CORNFORD, 1907, p. viii e 72). O ponto de partida da história tucidideana comportava, pois, espírito racional de observação reflexiva, voltado para a compreensão dos aspectos propriamente humanos dos acontecimentos. Certamente que Tucídides bem figurava, de princípio, os melhores sentimentos historiográficos de austera veracidade, um historiador consciente do precípuo dever de seu ofício (CORNFORD, 1907, p. 76).

Porém, à medida mesma em que a obra fora progredindo em sua narrativa dos acontecimentos, uma outra forma conceptiva se sobrepôs a esse primeiro plano, mais simples e rígido de perspectiva meramente factual. $\mathrm{O}$ reclamo, inerente à narrativa mesma, de alcançar uma inteligibilidade para o desenrolar dos acontecimentos bélicos que eram sucessivamente relatados, despertou em Tucídides a atualização de uma outra forma, artística, um princípio compositivo pelo qual, ele, Tucídides, selecionando na massa dos fatos os aspectos relevantes e consoantemente os ordenando, pudesse estabelecer os nexos vinculadores dos acontecimentos que melhor revelassem seu sentido histórico. Tucídides acabou valendo-se do paradigma existente em sua época: as concepções do drama ático, mais particularmente da tragédia esquileana, as quais comportavam uma filosofia da natureza humana, a qual esquematizava os modos ruinosos por que atuam as paixões excessivas dos homens.

Tal teoria filosófica, de conformação artística trágica, vinha exposta, já sob sua derivação tucidideana, no discurso acerca da sorte dos mitilênios, porque Diodoto se opusera à medida de extermínio e escravização dos revoltosos sustentada pelo discurso de Cleonte:

Na verdade tudo leva o homem a desafiar o perigo; a pobreza inspira a temeridade por obra da necessidade; já a riqueza o faz, pela jactância incontida da opulência; e as várias outras paixões humanas, por forças igualmente irreprimíveis, atuam sobre cada um nas diversas situações em que se encontram. Também a esperança e o desejo estão por toda a parte; o desejo conduz, a esperança segue; o desejo inspira os planos, a esperança promete os favores da sorte; os dois causam males terríveis, e sendo invisíveis, mostram-se mais fortes que os perigos visíveis. A sorte, juntando-se a outros fatores, não é incentivo menor; às vezes ela surge inesperadamente e induz os ho- 
mens ao perigo, mesmo sem recursos adequados; ... o homem então superestima irracionalmente sua própria força, porque, cegado seu espírito pela intoxicação que o veneno de uma inesperada Sorte, ou Fortuna, causa, superestima suas forças, abalando-se a enfrentar perigos muito além de seus poderes. Quando alcança este ponto, sua ruína está marcada, nada há que impeça seu curso fatal (TUCÍDIDES III.45.4).

Assim principia todo ruinoso destino trágico, de inelutável desfecho catastrófico.

A história de Tucídides estaria, pelas tramas da leitura de Cornford, mais próxima do gênero da poesia do que do da história, nos termos em que Aristóteles conceituara a oposição entre ambas na Poética. A história de Tucídides, assevera Cornford, é, pois, artística, em moldes dramáticos antigos, e não científica, em moldes realistas modernos.

A forma artística, dramática, por que Tucídides conformara sua história, introduzira-se, diz Cornford, em sua narrativa inerentemente à sua consecução mesma, não resultando, então, propriamente, de algum desígnio premeditado: fora o padrão de inteligibilidade a que os acontecimentos mesmos haviam induzido sua compreensão dos fatos, nele justamente ativando as perspectivas daquela filosofia trágica de seu tempo, que ele, como ateniense, tinha, a priori, inscrita em sua mente. E intriga filosófica tanto mais estruturadora de seu pensamento, porque efetuada por modos mais propriamente inconscientes: espécie de resíduo gravado na substância de seu cérebro, lá mais fortemente enraizado porque imperceptível (CORNFORD, 1907, p. 134-5).

A incipiente história analística então evoluíra por aderência de uma forma artística. E fora justamente em razão desta forma ou "unidade artística" que a história de Tucídides, afirma Cornford, tem apelo para o homem moderno, o seduz e fascina, antes do que pela insipidez austera de uma sua suposta cientificidade de registro factual (CORNFORD, 1907, p. 79-80).

No âmbito da unidade artística da obra, a tragédia fora reservada por Tucídides para a história de Atenas. Nesta tragédia maior, Cleonte atua como uma primeira instância, má conselheira, de persuasão enganadora (Peitho ou Apate), a envolver uma Atenas esperançosa de cobiças (Elpis) em cometimentos bélicos que, embora despropositados, alcançam (fugaz) êxito (o episódio de Pilos) (CORNFORD, 1907, p. 172). A ele se segue Alcibíades, outra figura de caráter na composição tucidideana. Primeiro atua como personificação de Apate (Engano) por que ascende ao palco da política ateniense, assim ganhando a simpatia 
popular ao vitimar os espartanos por suas manobras de traiçoeiras leviandades (CORNFORD, 1907, p. 189). Com o incidente da subjugação e massacre da população de Melos, Atenas já figura Hybris, assim tomada em sua decisão pela crueldade violenta de soberba loucura, cegada por já desenfreada cobiça. A mente da cidade adoeceu incurável (CORNFORD, 1907, p. 201). O transmissor da doença: Eros Tyrannos (Desejo Despótico), também personificado por Alcibíades, que, encenando o sedutor Amante do Povo, incendeia desejos de conquistas e glórias, agora ativando o projeto de expedição contra a Sicília. Tempo de desvario de Atenas, princípio de sua ruína trágica, consumada pela total aniquilação das suas, entretanto, portentosas forças militares. Tucídides a descreveu, por tons de grandiosa dramaticidade, na parte de sua história que compõe o livro VII.

Assim, argumenta Cornford, adentraram o palco da história de Tucídides os personagens figurativos das tragédias atenienses, especialmente esquileanas: Tychê, Elpis, Apatê, Hybris, Eros, Phthonos, Nemesis, Atê (CORNFORD, 1907, p. 220). A história de Tucídides compusera, pois, uma tragédia de Atenas: "pelo decurso sequencial dos episódios do Discurso Fúnebre de Péricles, da campanha de Pilos, do diálogo de Melos e da expedição à Sicília, vislumbram-se os desvios hibrísticos de ambições imperiais desmedidas, infladas em sua avidez de ganhos por golpes inesperados de sorte próspera, logo, entretanto, revirada em infortúnio consequente à perda da lucidez racional, por que a cidade, agora cega de paixões, errava em suas decisões" (PIRES, 1999, p. 9).

Tucídides, ao inspirar-se, pois, na estrutura formal da tragédia esquileana, dela derivando uma teoria trágica da natureza humana, concomitantemente, em razão do temperamento de racionalidade positiva que dominava na Atenas de seu tempo, introduziu o esquema trágico em sua história mas descarnando-o de sua substância teológica, de modo a preservar apenas seu aporte de moralidade. Ao fazê-lo, acrescenta Cornford, operou intrigante peripécia, pois acabou, ao desviarse da teologização filosófica esquileana, revertendo as concepções de sua história para os padrões de um estágio primevo do pensamento humano, aquele mais afeito a crenças míticas primitivas, pré-teológicas, acerca das figuras de agentes concebidos como associados aos processos desencadeadores de reversão de fortuna na história dos homens (CORNFORD, 1907, p. 221 e 236).

Tal evolução histórica do pensamento humano, entende Cornford, principiara por um estágio primitivo de pura religiosidade, que concentrava suas crenças na existência cósmica de figuras de daímones, espíritos exteriores, envoltos em tre- 
vas, cuja atuação comportava uma etiologia misteriosa, incompreensível, para os homens, deles reclamando reverência supersticiosa por consoantes ritos mágicos (CORNFORD, 1907, p. 223 e 242). A partir dessa forma primeira de religiosidade pura, o espírito humano evoluíra para outro estágio, agora teológico, em deslocando a concepção dos daímones pela dos deuses, particularmente representados, no caso dos gregos, pelos Deuses Olímpios. Por esta teologia olímpica projeta-se uma ideologia da ordem cósmica que estrutura uma radical hierarquia entre deuses e homens, por que se elabora uma explanação (isto é, já formulando uma etiologia melhor delineada) justificadora das reversões de fortuna humana, assim entendidas como punições ativadas exteriormente pela indignação dos deuses, então ofendidos pelas transgressões dos limites que os separavam dos homens por indivíduos arrogantes e presunçosos que pretendiam equiparar-se a eles (CORNFORD, 1907, p. 233 e 242). O terceiro estágio evolutivo acresce à formulação teológica uma abordagem moral: a causalidade divina das reversões de fortuna humana agora responde como justiciamento punitivo, ressarcidor de ofensas morais, atuando por meio das próprias paixões dos homens, as quais, assim, como que internalizam e incorporam humanamente os modos da causalidade divina. É esta filosofia trágica, que conjuga teologia com moral, que, diz Cornford, informara e acabara conformando as tragédias de Ésquilo (CORNFORD, 1907, p. 234-6 e 242).

Ao dar um passo além nesse processo de evolução racional positiva do pensamento humano, em o libertando de suas figuras teológicas, para apenas reter a moralidade que as tragédias de Ésquilo haviam embutido nessa filosofia da natureza humana, Tucídides projetava um quarto estágio de formulação intelectiva, de intúito racionalizante. O que dele, entretanto, resultou como desfecho de consecução de sua história, foi antes paradoxal, sentencia Cornford:

In thus removing the theological element, he has reverted in a curious way to the pre-theological conception of the tragic fact, which existed long before Aeschylus. The language of Diodotus expresses that conception in its completeness and with great precision. We have in fact in that statement an instance of rationalizing. The accretion of theological belief is removed; but what is left is a mythical construction which contains and carries with it conceptions still more primitive (...) so in rationalizing the theology of Aeschylus, he was unaware that what remained was mythical in origin, and not a fresh statement of the facts of life drawn from direct and unbiassed observation (CORNFORD, 1907, p. 242). 
Por tais tramas de argumentação analítica com que Cornford propunha sua interpretação acerca da história tucidideana, a intriga polemizante face a seus contemporâneos de inícios do século XX se tornava clara, e mesmo algo perversa: a história de Tucídides não se constituía numa afirmação do espírito positivo do lógos científico no âmbito historiográfico, como o supusera a "falácia modernista", antes, sustenta Cornford, o levou a fazer com que a história recaísse no horizonte filosófico do mítico. A história de Tucídides resultara Mithistória.

Para quais horizontes de paradigmas teóricos, então, a leitura de Cornford deslocava a hermenêutica da obra tucidideana, respondia por uma contextualização epistemológica muito bem definida. Francis Macdonald Cornford integrou, ao lado de Gilbert Murray pelas primeiras décadas do século XX, o grupo que se convencionou denominar os Ritualistas de Cambridge. Figura central do grupo, Jane Ellen Harrison: seu "coração, em mais de um sentido" diz, algo maliciosamente, um crítico recente (Thomas W. Africa). Outro crítico a imagina como uma como emblemática deusa minóica, soberanamente ladeada por duas feras masculinas.

É ela, Jane Harrison, quem ordena todo o mapa de referências teóricas porque o grupo deveria orientar suas reflexões, assim deles reclamando a leitura de Marx, de Nietzche, de Freud, de Bergson, etc.

A sombra de Jane Harrison sobrepaira a concepção do Mythistoricus, nele aparecendo já no princípio da obra por epígrafes e dedicatórias nela inspiradas. O jovem Fellow of Trinity College, então com 33 anos, membro de um grupo que tentava nada menos do que uma revolução nos estudos clássicos, consagra, como dedicatória à mentora do grupo uma curta frase que reformula ligeiramente uma fala de Sócrates a Teeteto: "Ouça, então, um sonho em retribuição a vosso sonho" (CORNFORD, 1907, p. 62).

Cornford, pois, associara sua leitura tucidideana aos projetos de Jane Harrison: reagia-se contra a tradição hegemônica que percebia o helenismo clássico como a realização primorosa da razão humana na Antiguidade, de que Tucídides era especialmente saudado como um de seus arautos modelares. Por esse télos, Cornford buscou dissociar a interpretação de Tucídides dos ditames da questão da cientificidade, direcionando seu enfoque justo para o polo dela reverso: destacar, também em Tucídides, a força da presença dos modos míticos, mais primitivos, do pensamento humano, antes remetendo às práticas rituais originárias de sua história, equacionadoras dos ímpetos e emoções coletivas mais elementares e primevas, quer religiosas quer pré ou mesmo ir-racionais. "Escolher, nestas condições, a fina flor do racionalismo grego, é estratégia feliz”, ponderou François Hartog (HARTOG, 1982, p. 29-30). 
Sob a superfície apolínea da hermenêutica cientificista do texto tucidideano, a leitura de Cornford intentava desvendar o fundo dionisíaco, de viés mítico e trágico. A história tucididiana rescendia, pois, não propriamente ao científico, mas antes ao mítico, revelando uma confusão de identidades que justamente o título da obra de Cornford estigmatizava em síntese "provocativa": Thucydides Mythistoricus.

Tucídides descaia (ou se elevava?) dos lados da ciência para os da arte, especialmente dramática. Dualidade hermenêutica pendular de velha herança, que agora a leitura de Cornford impulsionava no sentido reverso. A ótica por que se devesse enfocar a inteligibilidade histórica da obra de Tucídides deixaria de estar voltada para aquela orientação de uma miragem futurista moderna, então polarizada pelas aspirações cientificistas dos séculos XIX e inícios do XX, para, agora com Cornford, retomar suas heranças arcaicas passadas, de fundos mitológicos, que, atualizadas na contemporaneidade de Tucídides, apontavam para séculos bem anteriores ao $\mathrm{V} \stackrel{\mathrm{a}}{\mathrm{C}} \mathrm{C}$.

Volta de Tucídides aos princípios mais fundos da História. Mas, volta fugaz, pois, logo depois de Cornford, o pêndulo reverteria novamente sua força gravitacional, afastando-se da artística atraído pela científica, e depois ...

\section{Notas}

* Professor Titular do PPG História Social e do Curso de Graduação em História da FFLCH/USP.

1 "Empecemos con Tucídides. Tiempo atrás escribí un libro con el título provocador de Thucydides Mythistoricus. No pretendi poner en duda la aserción de Tucídides de ser quizás el más digno de confianza de entre todos los historiadores. Mi tesis no deslizó necesariamente duda alguna sobre ninguna constatación separada de un hecho objetivo" (Cornford, 1921, p. 28)

2 "If this appreciation of the historian is sympathetic, I hope you will not suppose that I belong to the band of devotees who make a cult of Thucydides and can see no defects in their idol. Such devotees existed in ancient as well as in modern times, and the historian's ancient indiscriminating admirers received a very proper rebuke from Dionysius of Halicarnassus" (146). 


\section{REFERÊNCIAS BibLIOGRÁICAS}

AFRICA, Thomas W. Aunt Glegg Among the Dons or Taking Jane Harrison at Her World. In: CALDER, W. M. (ed.). The Cambridge Ritualists Reconsidered. Atlanta: Scholars Press, 1989. p. 21-36.

CORNFORD, F. M. Thucydides Mythistoricus. London: 1907.

HARTOG, F. L’oeil de Thcydide et l'histoire véritable. Poétique, 49, p. 22-30, 1982.

PIRES, F. M. Mithistória, São Paulo: Humanitas, 1999.

TUCÍDIDES. História da Guerra do Peloponeso. Trad., intr. e notas de Mário da Gama Kury. Brasília: Edit. Universidade de Brasília, 1982.

PIRES, Francisco Murari . Myth and tragedy in Thucydides: lessons by Francis M. Cornford.

ABSTRACT: The article proposes to delineate analitically the hermeneutic of a pattern of tragic composition in Thucydides' History proposed by Francis M. Conford appreciating this hermeneutic in the historical context of the words od the Cambridge Ritualists.

KEY WORDS: Thucydides; Francis M. Cornford; history; tragedy; Cambridge Ritualistics. 